\title{
Epitaxical nucleation of polycrystalline silicon carbide during chemical vapor deposition
}

\author{
Brian W. Sheldon \\ Division of Engineering, Brown University, Providence, Rhode Island 02912, and Oak Ridge Associated \\ Universities, Oak Ridge, Tennessee 37831
}

Theodore M. Besmann, Karren L. More, and Thomas S. Moss

Metals and Ceramics Division, Oak Ridge National Laboratory, Oak Ridge, Tennessee 37831

(Received 17 June 1992; accepted 12 January 1993)

\begin{abstract}
Polycrystalline silicon carbide was deposited from methyltrichlorosilane in cold-walled and hot-walled reactors, on (100) SiC surface layers that were formed on (100) Si wafers. The initial stages of the process were studied by electron microscopy after relatively short deposition times. Submicron surface features nucleated with a specific crystallographic orientation with respect to the substrate, where $\{111\}$ planes in the $\beta$-SiC substrate coincided with $\{0001\}$ planes in the $\alpha-\mathrm{SiC}$ features. These $\alpha-\mathrm{SiC}$ features occurred only at twins on $\{111\}$ planes of the $\beta-\mathrm{SiC}$ substrate. This demonstrates that nucleation under these conditions is controlled by defects in the substrate. Surface contamination and the reactor configuration also had substantial effects on nucleation.
\end{abstract}

\section{INTRODUCTION}

Polycrystalline $\mathrm{SiC}$ produced by chemical vapor deposition (CVD) exhibits a wide range of different microstructures that have, in many cases, been empirically correlated to various processing parameters. ${ }^{1,2}$ Most of the research conducted on nucleation and growth mechanisms during CVD has focused on the epitaxical growth of single crystals, with particular emphasis on the formation of electronic materials such as $\mathrm{Si}$. This previous work provides a starting point for understanding the formation of polycrystalline materials. Although the nucleation and growth of polycrystalline Si have been studied in detail, ${ }^{3-5}$ in general, the microstructure evolution of polycrystalline materials is not well understood.

Because of its high strength and chemical stability at elevated temperatures, $\mathrm{SiC}$ produced by CVD is potentially important for protective coatings. There is also considerable interest in forming ceramic matrix composites by performing CVD in a porous structure (known as chemical vapor infiltration or CVI).$^{6-9}$ Research on the deposition of polycrystalline $\mathrm{SiC}$ is thus primarily of interest for high-temperature coatings and structural materials. Some of the knowledge obtained may also be relevant to the formation of single-crystal $\mathrm{SiC}$ thin films that are currently of interest for electronic applications.

The research presented here describes the CVD of $\mathrm{SiC}$ on $\mathrm{SiC}$ surfaces. This is a relatively simple system that is also the basis for related work on the development of laser light-scattering as an in situ method for monitoring nucleation and growth. Preliminary results with this optical technique are described elsewhere. ${ }^{10,11}$

\section{DESCRIPTION OF EXPERIMENTS}

Deposition was conducted with two different reactor configurations. Figure 1 depicts a hot-wall system, where the graphite tube surrounding the sample was heated by a radio-frequency (RF) generator operating at $455 \mathrm{kHz}$. A corresponding cold-wall configuration was also used where the graphite tube (shown in Fig. 1) was not present, so that the SiC-coated graphite sample holder acted as a susceptor in the RF field. The substrate temperature was measured with an optical pyrometer that was focused through a calibrated window and onto the graphite holder.

The substrates used for this work were (100) oriented $\mathrm{Si}$. Prior to $\mathrm{SiC}$ deposition, the substrate was heated rapidly to $1350{ }^{\circ} \mathrm{C}$ at approximately 500 $700{ }^{\circ} \mathrm{C} / \mathrm{min}$ in a flowing stream of $\mathrm{H}_{2}\left(5000 \mathrm{~cm}^{3} / \mathrm{min}\right)$

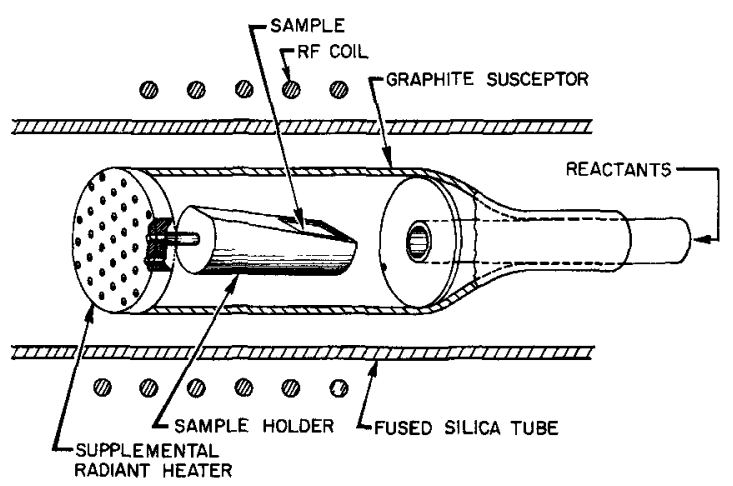

FIG. 1. Schematic of the hot-walled CVD reactor. 
and $\mathrm{C}_{2} \mathrm{H}_{4}\left(5.0 \mathrm{~cm}^{3} / \mathrm{min}\right)$ at atmospheric pressure. After this temperature was reached, the substrate was cooled to ambient temperature in flowing $\mathrm{H}_{2}$. Similar procedures have been used elsewhere to carburize Si surfaces prior to the deposition of $\mathrm{SiC}$ thin films. ${ }^{12-14}$ After preparing the substrate surfaces in this way, $\mathrm{SiC}$ was deposited from methyltrichlorosilane (MTS) in hydrogen; a variety of different processing conditions were used. Between the carburization and deposition procedures the substrates remained in the reactor in a flowing hydrogen atmosphere.

The sample surfaces were examined by scanning electron microscopy (SEM) using a JEOL 890 equipped with a field emission gun. Several samples were also examined by transmission electron microscopy (TEM). High-resolution electron microscopy (HREM) was performed using a JEOL 4000EX electron microscope operated at $400 \mathrm{kV}$. Images were recorded with a $1 \mathrm{mr}$ convergence semi-angle at Scherzer defocus $(\sim-47 \mathrm{~nm})$. The orientation relationships were determined using optical diffraction.

\section{RESULTS}

The early stages of deposition were studied with both reactor configurations, using a variety of different processing conditions. One of the primary objectives of this study was to determine conditions where the nucleation, growth, and coalescence of individual $\mathrm{SiC}$ clusters were slow enough to permit the direct observation of isolated surface features. These isolated features are better suited to electron diffraction studies because a single crystallite can be analyzed without other material at a different orientation contributing to the diffraction data. Also, microstructural evolution is easier to study if it occurs at a relatively slow rate, especially during the initial stages of the CVD of poly-

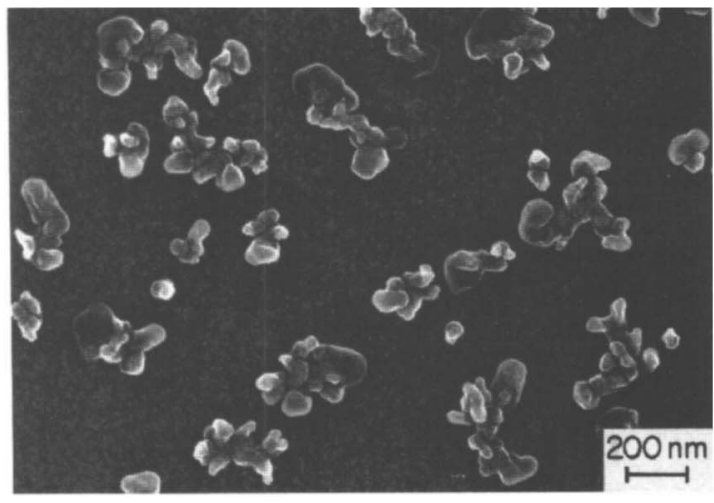

(a) crystalline materials, when the microstructure usually changes rapidly. The formation of isolated features at a relatively slow rate is particularly conducive to detailed analysis because the nucleation and growth rates can be measured by examining a series of micrographs or with light-scattering. ${ }^{4,11}$ To produce isolated features, deposition was conducted at a relatively low pressure $(2.6 \mathrm{kPa})$ and at relatively low temperatures $\left(950{ }^{\circ} \mathrm{C}\right.$ or $1000{ }^{\circ} \mathrm{C}$ ). Lower temperatures were not studied because Si forms instead of SiC. ${ }^{15,16}$ Thus the growth rate and microstructure were controlled primarily by varying the gas composition and exposure time.

Figure 2 shows SEM micrographs of material that was deposited on carburized substrates at $1000{ }^{\circ} \mathrm{C}$ for $30 \mathrm{~s}$, using both reactor configurations with $2.4 \% \mathrm{MTS}$ in $\mathrm{H}_{2}$. A continuous layer of polycrystalline $\mathrm{SiC}$ formed in the hot-walled system [Fig. 2(b)], while isolated surface features formed in the cold-walled system [Fig. 2(a)]. The clustering of these features indicates that a significant amount of nucleation has occurred preferentially on existing features.

Figure 3 is an SEM micrograph of a surface formed at $950{ }^{\circ} \mathrm{C}$ using $2.4 \%$ MTS in the hot-walled system. In this case, isolated surface features are seen instead of the clustering observed in Fig. 2(a). At longer deposition times, the individual features seen in Fig. 3 grew and coalesced into a continuous layer, similar to Fig. 2(b). The grain size gradually increases as the film continues to grow away from the substrate, which is common during the CVD of polycrystalline materials. An example of these larger features is shown in Fig. 4, after a deposition time of $240 \mathrm{~s}$. At higher temperatures and MTS concentrations, continuous films were observed after only 10 or $15 \mathrm{~s}$.

The sample shown in Fig. 3 was examined in cross section by HREM. Carburizing the Si surface produced a relatively smooth $\sim 20 \mathrm{~nm}$ thick $\beta-\mathrm{SiC}$ (cubic structure)

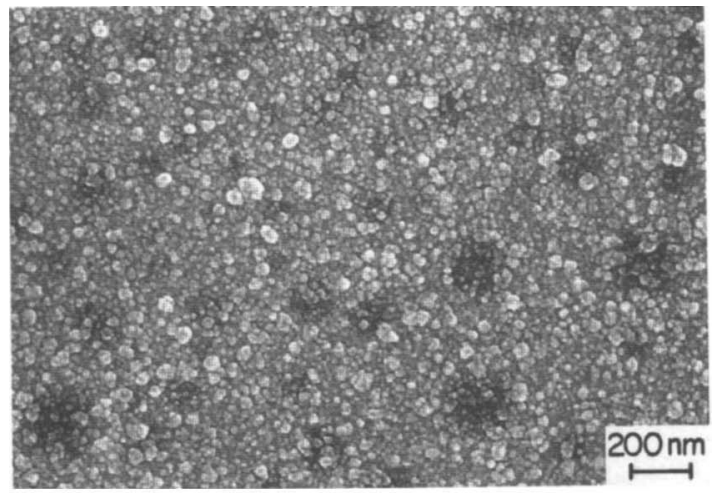

(b)

FIG. 2. SEM micrographs after CVD at $1000{ }^{\circ} \mathrm{C}$ and $2.6 \mathrm{kPa}$ for $30 \mathrm{~s}$, with $2.4 \%$ MTS in $\mathrm{H}_{2}$. (a) Material deposited with the cold-walled configuration. (b) Material deposited with the hot-walled configuration. 